\title{
Corrosion Activity on CFRP-Strengthened RC Piles of High-Pile Wharf in a Simulated Marine Environment
}

\author{
Ning Zhuang, ${ }^{1,2}$ Yujue Zhou, ${ }^{1,2}$ Yeming Ma, ${ }^{1,2}$ Yingdi Liao, ${ }^{1,2}$ and Da Chen ${ }^{1,2}$ \\ ${ }^{1}$ Jiangsu Key Laboratory of Coast Ocean Resources Development and Environment Security, Hohai University, Nanjing, China \\ ${ }^{2}$ College of Harbour, Coastal and Offshore Engineering, Hohai University, Nanjing, China
}

Correspondence should be addressed to Da Chen; chenda@hhu.edu.cn

Received 1 November 2016; Accepted 16 January 2017; Published 5 February 2017

Academic Editor: Carlo Santulli

Copyright (C) 2017 Ning Zhuang et al. This is an open access article distributed under the Creative Commons Attribution License, which permits unrestricted use, distribution, and reproduction in any medium, provided the original work is properly cited.

\begin{abstract}
We report test results from an experimental study to investigate the effectiveness of carbon fiber-reinforced polymer (CFRP) against reinforcing steel bar corrosion. Twelve reinforced-concrete pile specimens of $180 \mathrm{~mm}$ square by $1,600 \mathrm{~mm}$ long were cast. Three pile specimens were corroded to 5\% steel mass loss and then strengthened with CFRP sheets; four specimens were strengthened by using CFRP sheets, whereas the remaining five specimens were not strengthened. The specimens were placed in a simulated marine environment, and corrosion was induced by an impressed current technique. At different theoretical corrosion degrees, nondestructive tests were performed to investigate the corrosion activity of the pile specimens, and destructive tests were performed to determine reinforcing steel bar mass loss. Based on the findings, the effectiveness of the CFRP-strengthened RC piles under aggressive marine environmental conditions was established.
\end{abstract}

\section{Introduction}

The deterioration of marine reinforced-concrete (RC) structures induced by reinforcing steel bar corrosion is a global problem [1]. In general, concrete provides a highly alkaline environment, which results in the formation of a passivation membrane that protects steel bars from being corroded. Reinforcing steel bars in concrete structures are depassivated as chloride concentrations reach threshold levels on the rebar surface or when the $\mathrm{pH}$ of the concrete cover is reduced below critical levels because of carbonation [2]. Marine structures, especially RC pile foundation of high-pile wharf, experience reinforcement corrosion, because their concrete face is often wetted periodically by tidal levels, and dry-wet environments supply reinforcement corrosion with three necessary conditions: sufficient chloride ions, moisture, and oxygen. Temperature variations make it easy for chloride ions to reach the reinforcement or to decrease the $\mathrm{pH}$ of the concrete cover. As reinforcement corrosion is initiated, it progresses by volumetric expansion of the rust around the rebar.

Traditionally, reinforcement corrosion damage has been repaired by "chip and patch" methods in which the deteriorated concrete is removed; then the corroded steel bar is cleaned, and patching mortar is applied. After repair, rerepair is common for the poor corrosion resistance of mortar materials.

Carbon fiber-reinforced polymers (CFRP) are lightweight, high-strength, and excellent corrosion resistance materials that have been used as an alternative material to strengthen structures and serve as barrier elements to carbon dioxide, chloride, and moisture ingress that promotes corrosion reactions in harsh marine environments [3, 4]. Several researchers have investigated the behavior of concrete members encased with CFRP sheets that were subjected to harsh environmental conditions such as temperature variations $[5,6]$, wet-dry cycles [7-9], freezing and thawing cycles [10-13], temperature extremes [14-16], and high chloride concentrations [17-19].

Because of the aggressive marine environment, the deterioration of concrete pile for high-pile wharfs usually does not occur from one harsh condition type only. However, no detailed information exists in the literature on reinforcement corrosion that is caused by multiple harsh conditions in the marine environment. We conducted an accelerated corrosion experiment to investigate the behavior of concrete piles that are encased with CFRP sheets when subjected to multiple 
TABLE 1: Test program.

\begin{tabular}{lccccc}
\hline \multirow{2}{*}{ Specimen groups } & & \multicolumn{3}{c}{ Corrosion degree (\% steel mass loss) } \\
& 0 & $5 \%$ & $10 \%$ & CF5-15 & CF5-20 \\
\hline Poststrengthened & - & - & CF5-10 & CF10 & CF15 \\
Strengthened & - & CF5 & N10 & N15 & N20 \\
Unstrengthened & N0 & N5 &
\end{tabular}

Notes. CF5-10 denotes that a pile specimen firstly corroded to 5\% steel mass loss, then was strengthened by CFRP, and corroded to $10 \%$ steel mass loss. N10 denotes an unstrengthened pile specimen that was subjected to $10 \%$ steel mass loss.

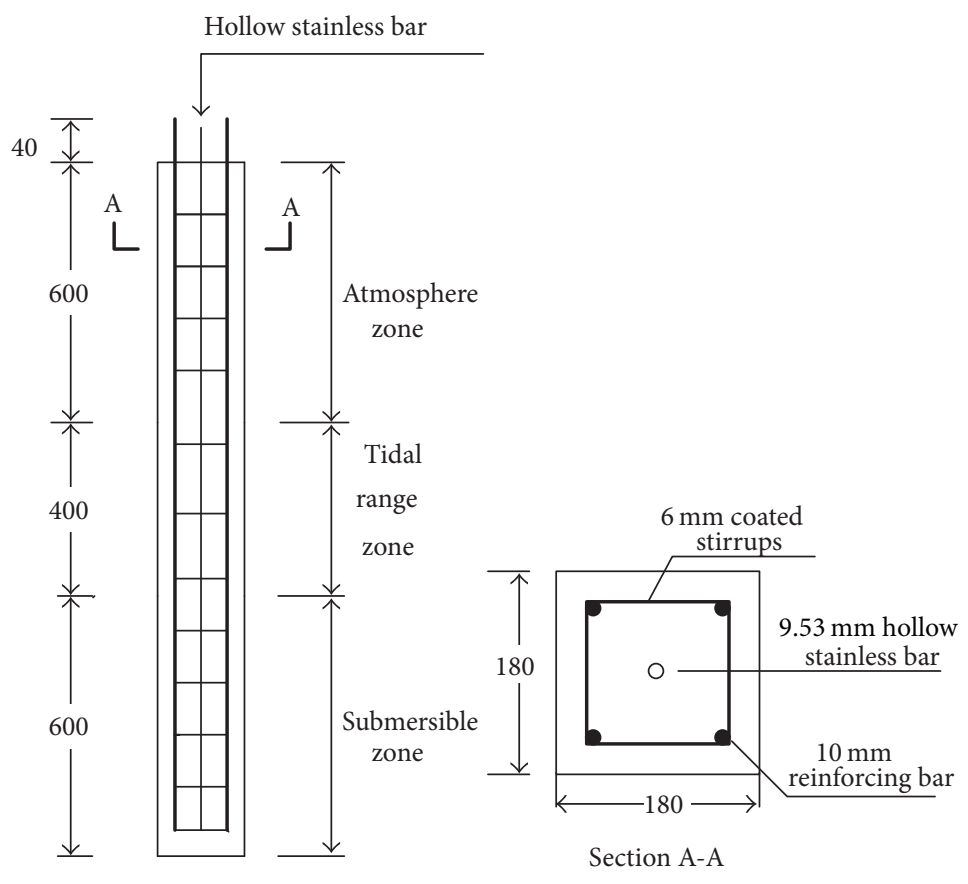

FIGURE 1: Specimen geometry $(\mathrm{mm})$.

simulated environmental conditions of temperature variations, high chloride concentrations, and wet-dry cycles.

\section{Experimental Program}

Twelve one-fifth scale models of 1,600 mm long and $180 \mathrm{~mm}$ square RC piles were cast. These prototype piles are used widely in South China coastal port engineering (Figure 1). Four $10 \mathrm{~mm}$ diameter longitudinal reinforcing bars were used for compression reinforcement with a clear cover of $40 \mathrm{~mm}$, and $6 \mathrm{~mm}$ diameter plain stirrups were spaced at $120 \mathrm{~mm}$. The tidal range zone of the pile specimen was $400 \mathrm{~mm}$ in the middle of the pile. A $9.53 \mathrm{~mm}$ diameter hollow stainless steel bar was provided at the center of the pile cross section to serve as an internal cathode for an impressed current to accelerate corrosion.

Specimens were divided into three groups: strengthened, unstrengthened, and poststrengthened specimens, as shown in Table 1. The reinforcing steel bar of the pile specimens in the poststrengthened group was corroded to $5 \%$ steel mass loss, then strengthened with CFFRP sheet, and subjected to further corrosion. The pile specimen of N0 that was not corroded in the unstrengthened group was the control pile in the test. Specimens that were strengthened or poststrengthened were encased over a $400 \mathrm{~mm}$ length by using CFRP sheet in the middle tidal range zone. Each pile specimen contained seven mounted strain gauges to monitor the deformation by expansion of the reinforcement corrosion, as shown in Figure 2.

\section{Material Properties}

The concrete mix proportion by weight was cement: sand: gravel $: \mathrm{w} / \mathrm{c}=1: 1.11: 2.72: 0.38$. The 28 -day concrete compressive strength was $31 \pm 1.2 \mathrm{MPa}$. The compression reinforcement in all pile specimens was $10 \mathrm{~mm}$ nominal diameter steel with a yield strength of $335 \mathrm{MPa}$ and an ultimate strength of $445 \mathrm{MPa}$. The $6 \mathrm{~mm}$ diameter plain bars used for stirrups had a yield strength of $240 \mathrm{MPa}$ and an ultimate strength of $380 \mathrm{MPa}$. The cured CFRP strips have a modulus of elasticity of $65 \mathrm{GPa}$, an ultimate tensile strength of $894 \mathrm{MPa}$, and an elongation of $1.33 \%$ at the breakage point, as reported by the manufacturer.

\section{Accelerated Corrosion Technique}

To complete the corrosion within a reasonable time, an accelerated corrosion technique based on Faraday's law was 


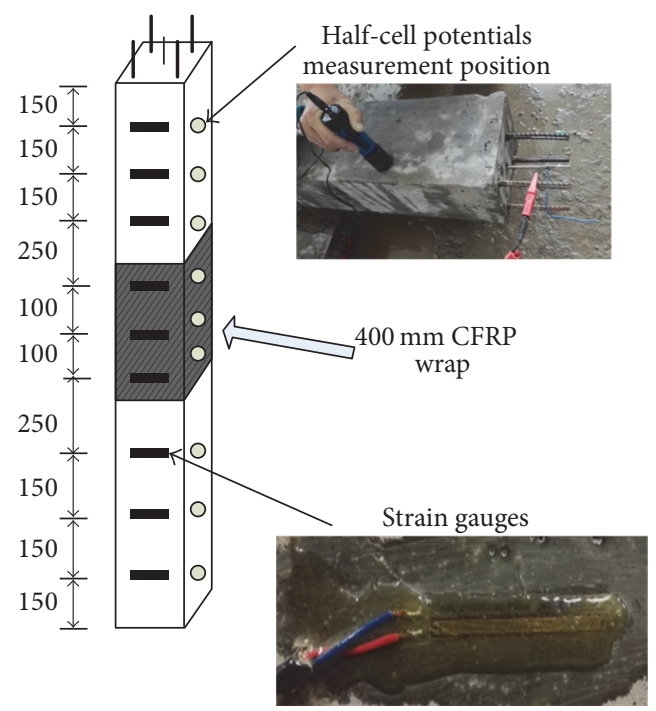

FIGURE 2: CFRP strengthening scheme and the measuring points $(\mathrm{mm})$.

used [20]. A constant-current system was built, and a direct current galvanostatic power supply was used to provide the desired current of $\sim 190 \mu \mathrm{A} / \mathrm{cm}^{2}$. The times to various degree of corrosion (steel mass loss) were estimated according to Faraday's law (e.g., the time to reach $10 \%$ mass loss was 45 days). Figure 3 shows the electrical connections of the accelerated corrosion system.

\section{Simulated Marine Environment}

To simulate tidal ranges in the marine environment, sea water levels were varied between the high and low tidal levels over $6 \mathrm{~h}$, as shown in Figure 4. Pile specimens were kept in the tank and were subjected to wet-dry cycles by artificially manufactured sea water with the chemical compositions in Table 2. A heater on top of the tank varied the temperature from $25^{\circ} \mathrm{C}$ to $40^{\circ} \mathrm{C}$ in $24 \mathrm{~h}$ to simulate average marine temperatures of the South China Sea region, as shown in Figure 5.

\section{Results and Discussion}

6.1. Corrosion Potential. Half-cell potential measurements are one of the most widely used nondestructive methods to monitor and assess steel bar corrosion in concrete structures $[21,22]$. It is generally agreed that the half-cell potential measurements can be interpreted according to ASTM C 87680 [23] in Table 3. In the test, all half-cell potential values of reinforcing bar were increased with the degree of corrosion as shown in Figure 6.

In the unstrengthened group, the corrosion potentials in tidal range zone were about $-350 \mathrm{mv},-612 \mathrm{mv},-705 \mathrm{mv}$, and $-810 \mathrm{mv}$ at $5 \%, 10 \%, 15 \%$, and $20 \%$ theoretical corrosion degree, which indicated that the rebar was in corrosion state from the corrosion degree of 5\%. In contrast, the atmosphere and full submersible zone were in active corrosion state from
TABLE 2: Chemical compounds in sea water.

\begin{tabular}{lc}
\hline Chemical compound & Concentration $(\mathrm{g} / \mathrm{L})$ \\
\hline $\mathrm{NaCl}$ & 24.53 \\
$\mathrm{MgCl}_{2}$ & 5.2 \\
$\mathrm{Na}_{2} \mathrm{SO}_{4}$ & 4.09 \\
$\mathrm{CaCl}_{2}$ & 1.16 \\
$\mathrm{KCl}$ & 0.695 \\
$\mathrm{NaHCO}$ & 0.201 \\
$\mathrm{KBr}_{3}$ & 0.101 \\
$\mathrm{H}_{3} \mathrm{BO}_{3}$ & 0.027 \\
$\mathrm{SrCl}_{2}$ & 0.025 \\
$\mathrm{NaF}$ & 0.003 \\
\hline
\end{tabular}

the corrosion degree of $10 \%$. Rebar in the tidal range zone was in more active corrosion state compared with other two zones because it was wetted by cyclic tidal level which could provide an adequate source of chloride ions, water, and oxygen compared to other zones.

For strengthened group, the CFRP repair has pronounced effect on slowing down corrosion velocity of piles. The potentials of tidal range zone were $-160 \mathrm{mV},-190 \mathrm{mV},-245 \mathrm{mV}$, and $-389 \mathrm{mV}$ and $54 \%, 69 \%, 65 \%$, and $52 \%$ greater compared to unstrengthened group piles at $5 \%, 10 \%, 15 \%$, and $20 \%$ corrosion degree, respectively. The analysis showed that the tidal range zone was greater than $90 \%$ probability of no active corrosion at $5 \%$ and $10 \%$ corrosion degree, active corrosion uncertain at $15 \%$ corrosion degree, and greater than $90 \%$ probability of active corrosion at $20 \%$ corrosion degree. Unlike the unstrengthened group, the potentials were positive compared to those of atmosphere and full submersible zone from $15 \%$ corrosion degree. It is because that the externally bonded CFRP effectively slowed down the corrosion velocity of the tidal range zone by preventing air and chloride ions from entering the concrete, which caused the potential curves to be flatter compared to the unstrengthened piles. As the tidal zone was encased with CFRP sheet, the atmosphere and the full submersible zone replaced casing tidal zone as the active region to suffer accelerating corrosion according to the mechanism of electrochemical corrosion. But because of the lack of aggressive medium in atmosphere and the full submersible zone, the average potentials of the atmosphere and the full submersible zone were also positive compared to those of unstrengthened group piles.

For poststrengthened group at $10 \%, 15 \%$, and $20 \%$ corrosion degree, corrosion potentials in the tidal range zone for poststrengthened piles were $26 \%, 36 \%$, and $44 \%$ more positive compared with unstrengthened group piles and $57 \%$, $46 \%$, and $14 \%$ more negative than those of strengthened group piles, respectively. The potentials increased more rapidly in the atmosphere and the full submersible zone than that of the tidal range zone as the piles were poststrengthened. The potentials for the poststrengthened group gradually reached those of the strengthened piles with increasing corrosion. The corrosion potentials for the atmosphere and the full submersible zone were more negative than the tidal range zone for a $15 \%$ corrosion degree, which is similar to 
TABLE 3: Dependence between potential and corrosion probability.

\begin{tabular}{lc}
\hline Potential & Probability of corrosion \\
\hline Ecorr $<-350 \mathrm{mV}$ & Greater than $90 \%$ probability that reinforcing steel corrosion is occurring \\
$-350 \mathrm{mV} \leq E \mathrm{corr} \leq-200 \mathrm{mV}$ & Corrosion activity of the reinforcing steel in that area is uncertain \\
$E$ corr $>-200 \mathrm{mV}$ & $90 \%$ probability that no reinforcing steel corrosion is occurring (10\% risk of corrosion) \\
\hline
\end{tabular}

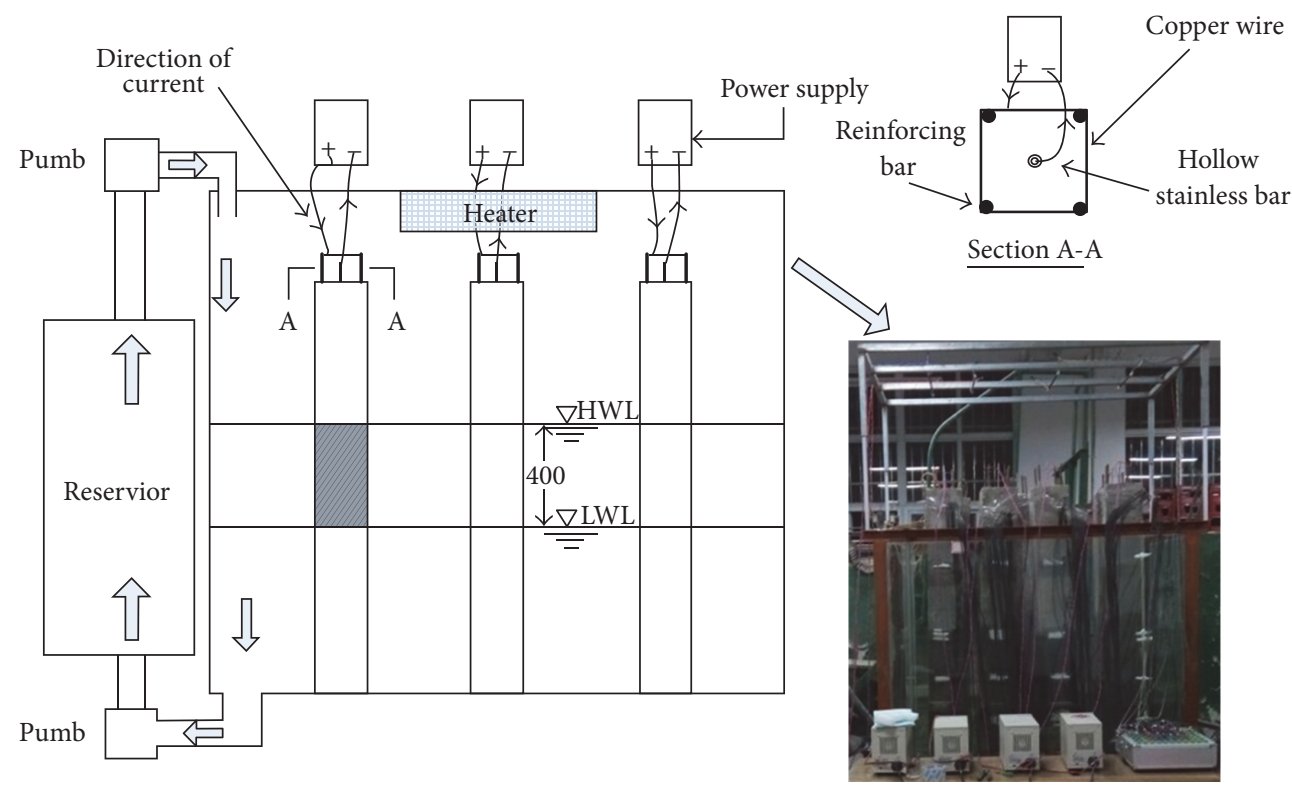

FIGURE 3: Marine environment simulation system and electrical connection.

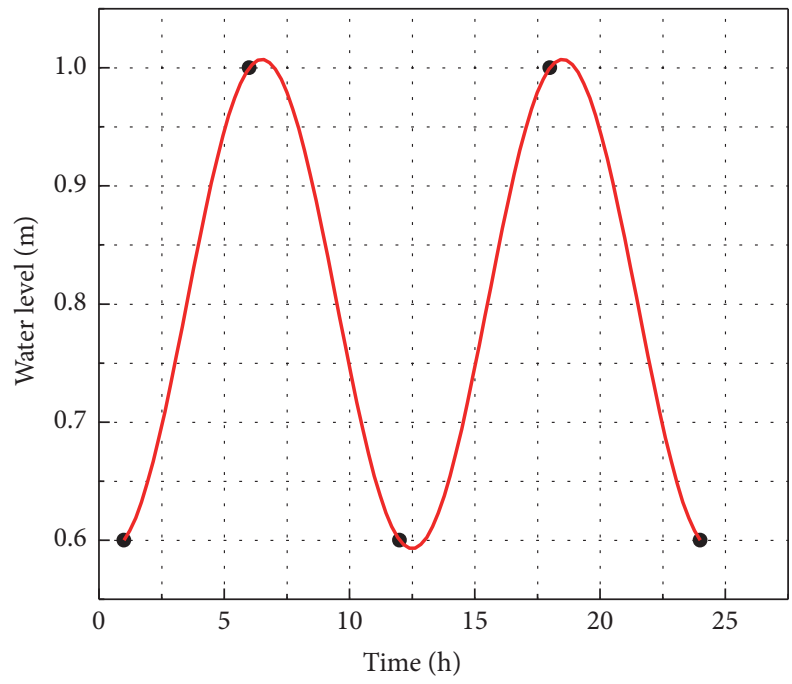

Figure 4: Tidal cycle of marine environment.

the strengthened group piles. Based on the variation characteristics of corrosion potentials during the whole period of accelerated corrosion, we could see that the speed of negative growth of poststrengthened specimens' corrosion potentials slowed down immediately compared with corresponding unstrengthened piles just after CFRP repaired. This made the unbalance potentials among atmosphere, tidal range, and

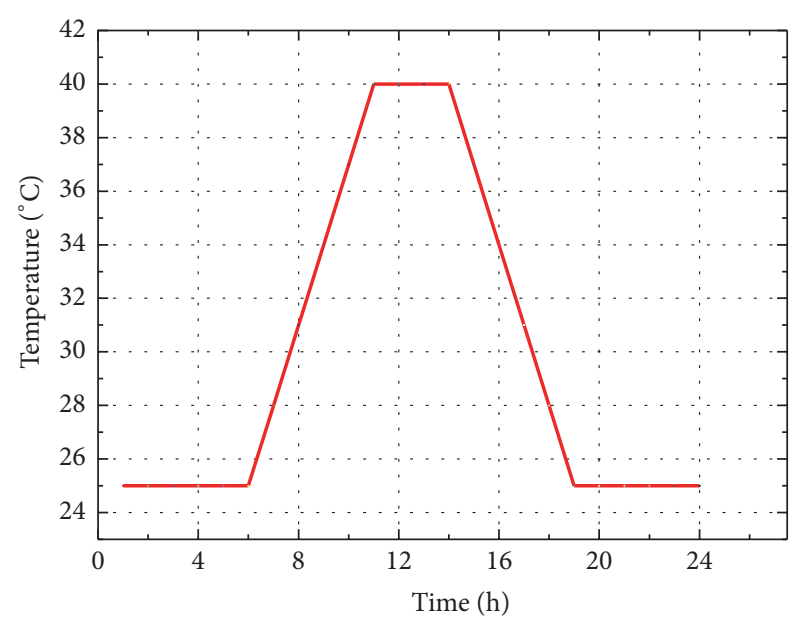

FIgURE 5: Temperature cycle of marine environment.

full submersible zones tend towards equilibrium. And such homogenization of corrosion potentials occurring inside the poststrengthened specimens would reduce the galvanic corrosion current of reinforcement due to the potential difference and then slow down the corrosion of reinforcement steel. This indicated that external bonded CFRP also had a very good effect on the piles that had already suffered nonuniform corrosion in some extent. 


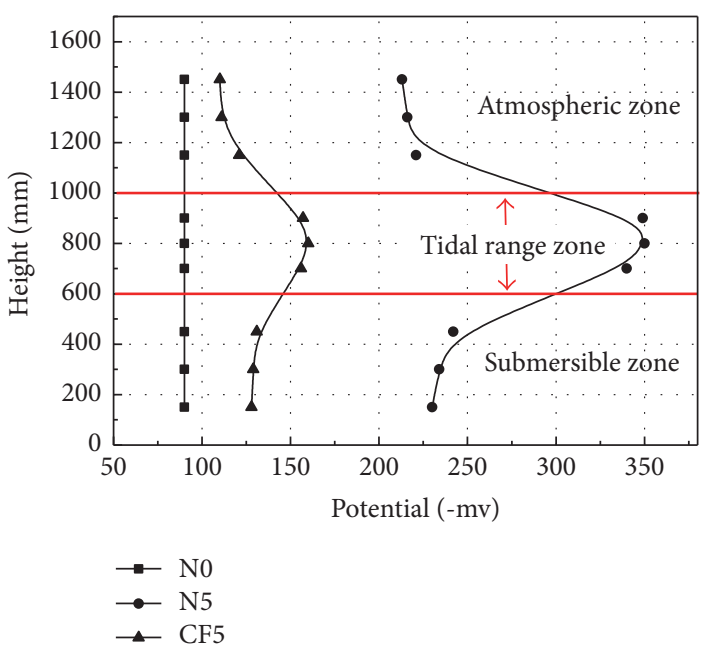

(a) $5 \%$ theoretical corrosion

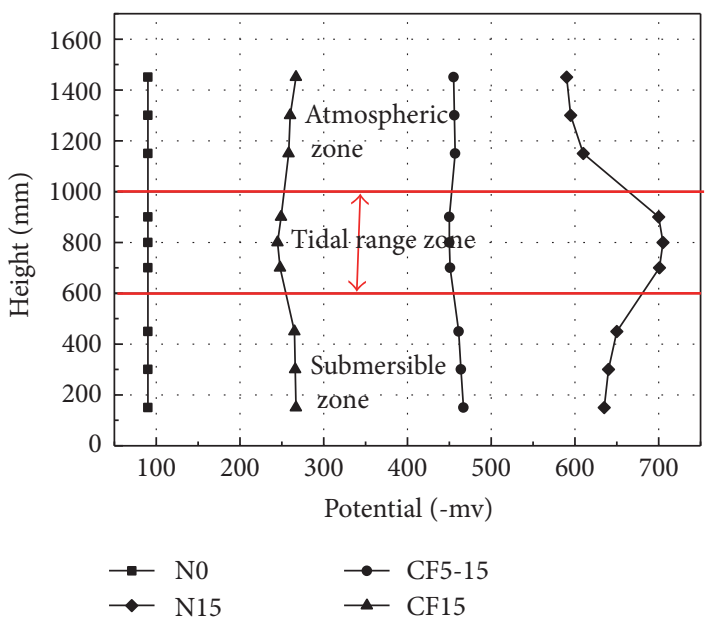

(c) $15 \%$ theoretical corrosion

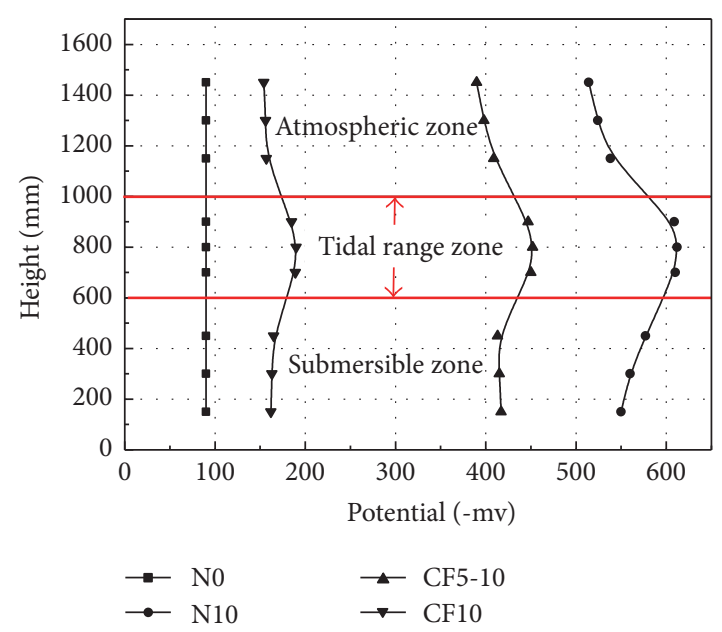

(b) $10 \%$ theoretical corrosion

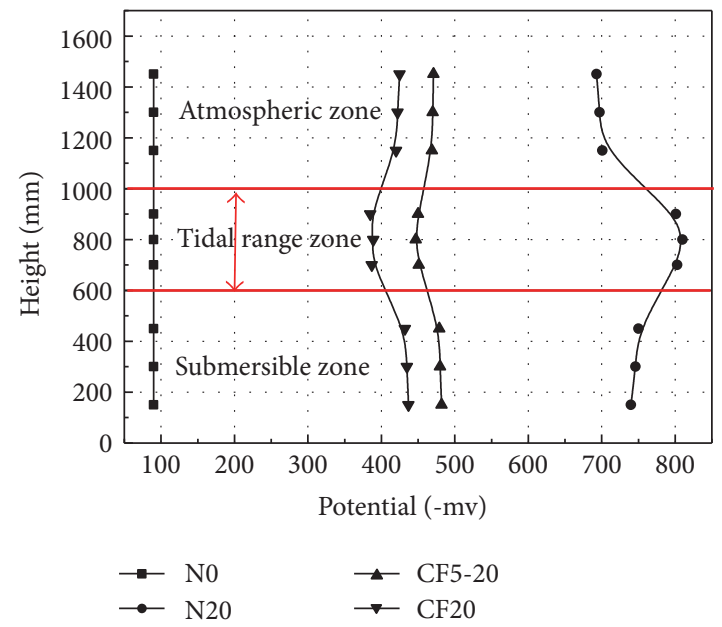

(d) $20 \%$ theoretical corrosion

Figure 6: Measured half-cell potentials of piles.

6.2. Steel Mass Loss. All specimens were tested gravimetrically to determine the actual degree of corrosion. Longitudinal cuts were made on the concrete surface with a diamondtipped saw, and the cover was chipped off with a hammer. Later, in accordance with ASTM Standard G1-90, the mass loss of reinforcing steel bars analysis was performed for each specimen in a different corrosion phase. The measured and predicted mass losses based on Faraday's law were compared in Figure 7 for all pile specimens at different corrosion degrees.

In the tidal range zone of the unstrengthened group, the measured steel mass loss for pile N5 was $6.2 \%$, which was slightly greater than the theoretical steel mass loss of $5 \%$, whereas the measured steel mass loss of piles $\mathrm{N} 10, \mathrm{~N} 15$, and N20 was $9.3 \%, 13.2 \%$, and $16.5 \%$, which is lower than the theoretical steel mass losses of $10 \%, 15 \%$, and $20 \%$, respectively. This occurs because of the penetration of corrosion products that build up around the reinforcing bar surface through surrounding concrete pores and form a physical barrier to prevent water and oxygen ingress, which slows their movement towards the bar surface [20]. The measured mass loss within the tidal range zone agrees well with Faraday's law for steel mass loss below 5\%, possibly because of the sufficient supply of humidity and oxygen needed for corrosion and because minimal physical barriers are formed in this region. The steel mass loss for the atmospheric and full submersible zone was smaller than that of the tidal range zone at the initial stage of corrosion and gradually approximated the value of the tidal range zone with an increase in corrosion.

The measured mass loss for poststrengthened piles of CF5-10, CF5-15, and CF5-20 in a tidal range zone was 27\%, $29 \%$, and $34 \%$ lower than that of unstrengthened piles of N10, $\mathrm{N} 15$, and $\mathrm{N} 20$ and was $92 \%, 80 \%$, and $63 \%$ greater than that of strengthened piles of CF10, CF15, and CF20, respectively. As the piles are strengthened with CFRP sheet in the tidal zone, the depolarization of chloride ion would decrease due to the isolation of chloride ion. This caused a sharp decrease in measured mass loss at a subsequent corrosion phase of $10 \%, 15 \%$, and $20 \%$ compared with the unstrengthened specimens. 


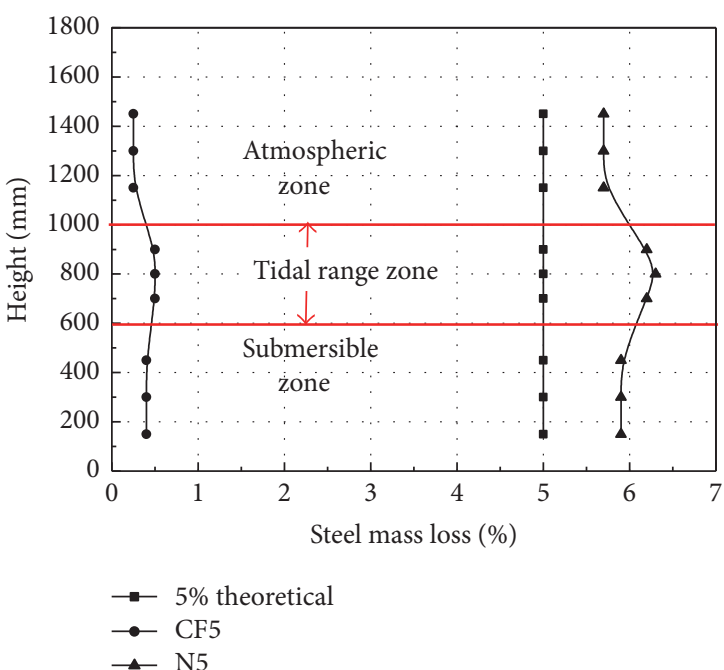

(a) $5 \%$ theoretical corrosion

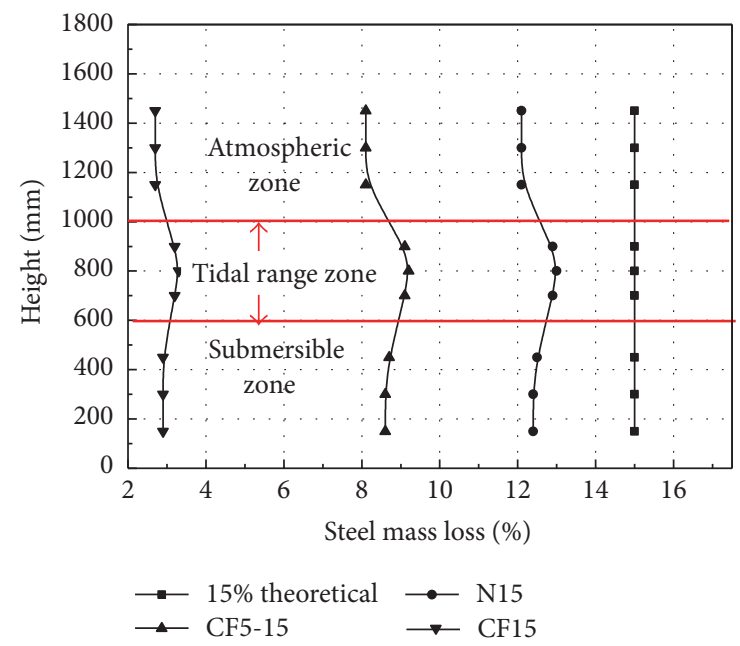

(c) $15 \%$ theoretical corrosion

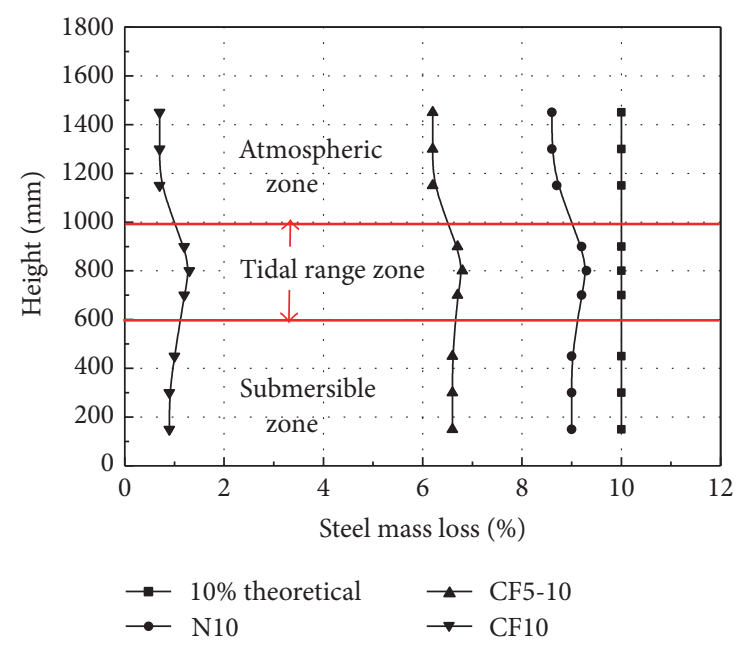

(b) $10 \%$ theoretical corrosion

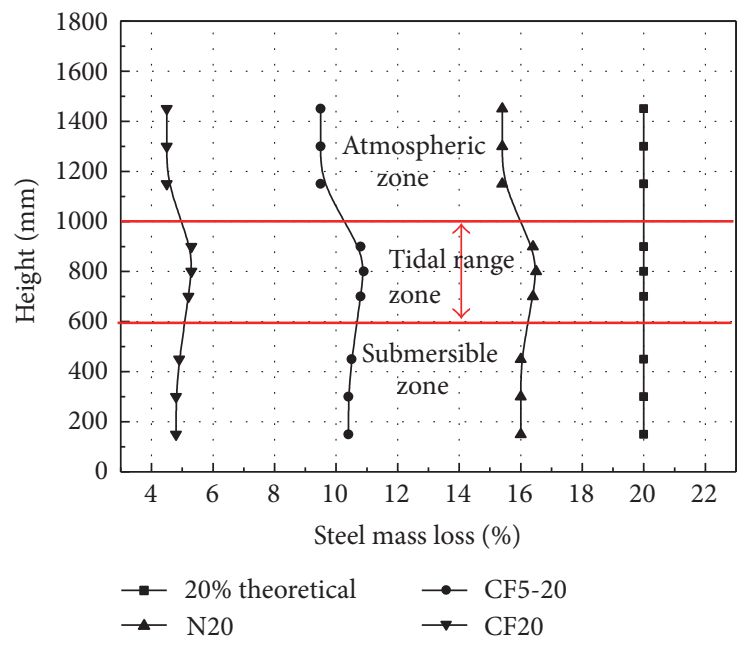

(d) $20 \%$ theoretical corrosion

FIgURE 7: Theoretical and measured steel mass loss.

As the ion channel was sealed by CFRP sheet in the tidal range zone of strengthened piles, the steel mass loss induced by corrosion was much smaller compared with poststrengthened and unstrengthened piles. The mass of strengthened pile CF 20 was $66 \%$ lower than that of unstrengthened pile $\mathrm{N} 20$ at the end of the corrosion. The steel mass loss of the atmospheric and full submersible zone was also lower compared with unstrengthened group piles because of CFRP strengthening. These results indicate that the effect of improving pile corrosion occurred by strengthening the piles with a CFRP sheet.

6.3. Corrosion Expansion. As the reinforcement corroded, the rust expanded more than six times in volume compared with the steel, as shown in Figure 8.

Due to the corrosion-induced expansive pressure in the unstrengthened piles, the strains of tidal zone were most severe, followed by the submersible zone and then the atmospheric zone (Figure 9), which is consistent with the

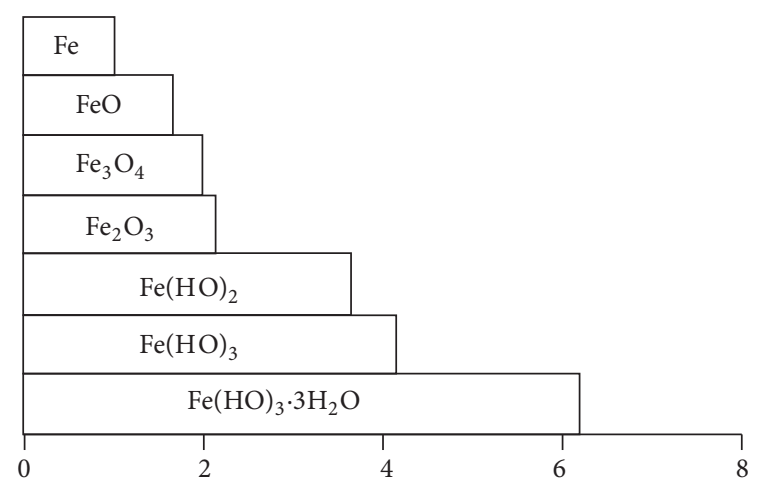

FIGURE 8: Relative volumes of different iron species.

variation characteristics of the half-cell potentials and steel mass loss. For unstrengthened piles, as the tidal range zone is the most seriously corroded zone during the whole corrosion 


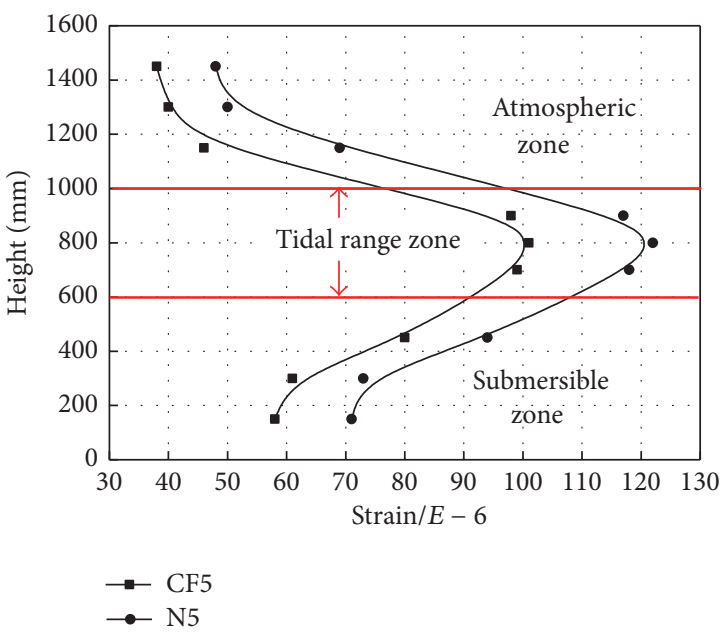

(a) $5 \%$ theoretical corrosion

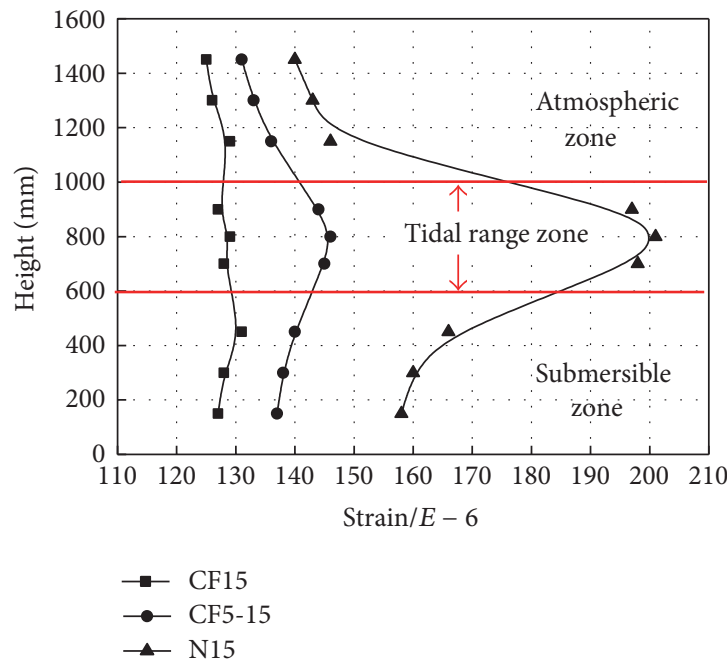

(c) $15 \%$ theoretical corrosion

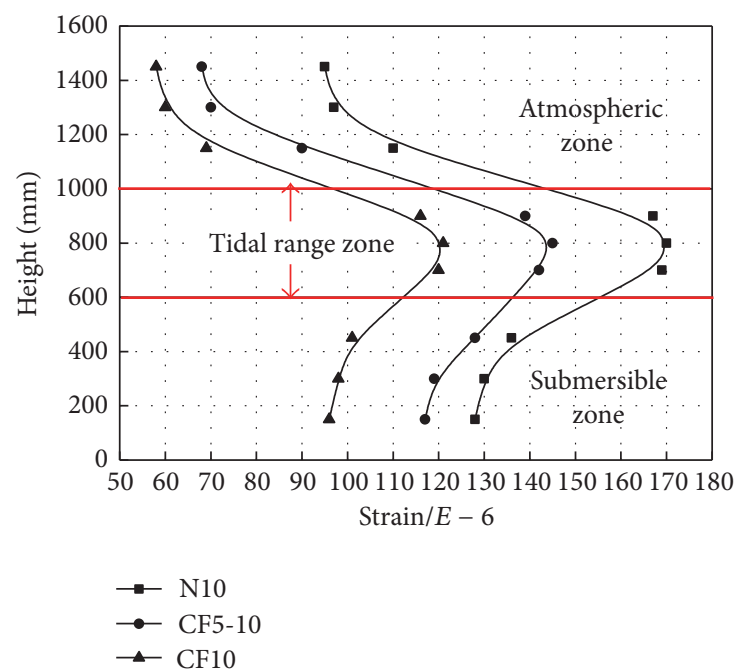

(b) $10 \%$ theoretical corrosion

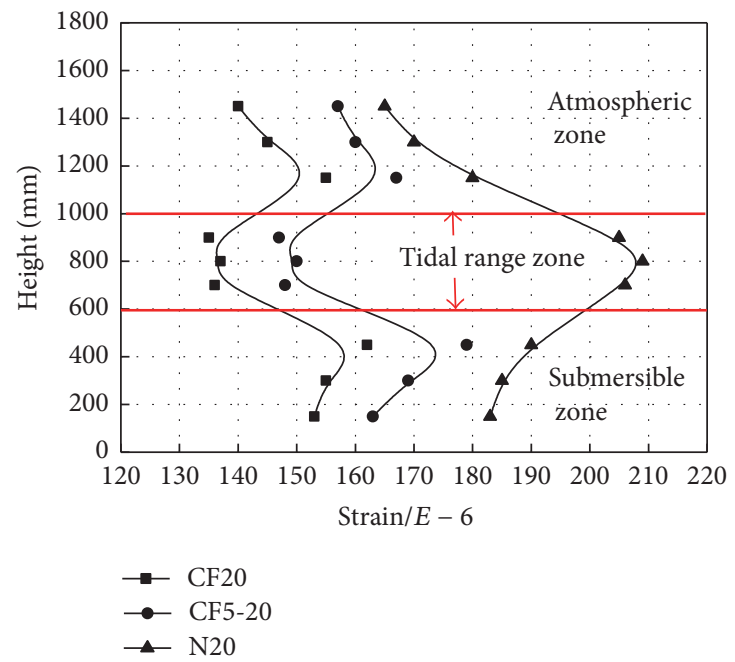

(d) $20 \%$ theoretical corrosion

FIGURE 9: Strains of piles at different corrosion degrees.

process, its strain is much greater than that of the atmospheric and full submersible zones. And the strain in the atmospheric zone was slightly lower than that of the submersible zone during the corrosion stage because of the high concentration of chloride ion in seawater.

To strengthen the piles, the tidal range zone was covered by CFRP sheet and cut off from the corrosive medium, which delayed its corrosion. So the strains of the strengthened piles were smaller compared with the unstrengthened piles during the corrosion stage. At a steel mass loss of $10 \%, 15 \%$, and $20 \%$, the strain in the tidal zone was $29 \%, 36 \%$, and $34 \%$ smaller than that of the unstrengthened piles and $17 \%, 12 \%$, and $9 \%$ smaller than that of the poststrengthened piles, respectively. The strain in the tidal range zone was on average $5.6 \%$ and $11.6 \%$ smaller than that of the atmospheric and submersible zones, respectively, at the end of the corrosion because of the constraining force of the CFRP sheet that limited concrete expansion in the tidal zone.
For poststrengthened piles, the strain of the tidal range zone was smaller than that of the unstrengthened piles as the corrosion degree exceeded 10\% because of the CFRP casing. The barrier formed by CFRP strengthening system in the tidal zone would significantly reduce the formation of the electrochemical system when the tidal zone was encased with CFRP at 5\% corrosion degree. So the tidal zone exhibited a decreased strain growth compared with the strains of the full submersible and atmospheric zone.

The strain in the tidal range zone was smaller than that of the atmospheric and submersible zone at the end of the corrosion degree of $20 \%$ because of the confinement of CFRP sheet, like that of the strengthened group piles. As the corrosion increased, the strain value of the poststrengthened piles approached that of the strengthened piles. This indicates that CFRP strengthening is also an effective method to repair RC piles that had served for several years in marine environment. 


\section{Conclusions}

This paper presents results of an experimental program that investigates the resistance to corrosion of piles strengthened with CFRP sheets subjected to a simulated marine environment. Based on the test results, the following can be concluded.

Encasing by using CFRP in the tidal range zone slowed the corrosion activity of the strengthened and poststrengthened piles. Piles encased with CFRP sheets provided excellent protection against corrosion compared with piles that were not strengthened, in terms of their steel mass loss rate, halfcell potential, and corrosion expansion.

Externally bonded CFRP sheets in the tidal range zone reduced the corrosion activity by up to $45 \%$ for the poststrengthened piles and 52\% for the strengthened piles compared with unstrengthened piles according to the half-cell potential at the end of the corrosion.

Because corrosion products built up around the reinforcing bars surface during accelerated corrosion based on Faraday's law, the steel mass losses measured in the test were smaller than those of the theoretical mass loss. The CFRP encasing confinement reduced the corrosion steel mass loss of the tidal range zone by $66 \%$ and $34 \%$ for the strengthened and poststrengthened piles, respectively, at a corrosion degree of $20 \%$ compared with the unstrengthened piles.

A confining of the corroded RC piles with CFRP sheets reduced the corrosion expansion of the tidal range zone by up to $28 \%$ for the poststrengthened and $34 \%$ for the strengthened piles compared with the unstrengthened piles at a corrosion degree of $20 \%$. Strains of the tidal range zone were smaller than those of the full submersible and atmospheric zone at the end of corrosion as the piles were strengthened.

\section{Competing Interests}

The authors declare that they have no competing interests.

\section{Acknowledgments}

This work was supported by the National Natural Science Foundation of China (51379073, 51679080, and 51509081) and the Natural Science Foundation of Jiangsu Province (BK20150037).

\section{References}

[1] E. Z. Beydokhti and H. Shariatmadar, "Strengthening and rehabilitation of exterior RC beam-column joints using carbonFRP jacketing," Materials and Structures/Materiaux et Constructions, pp. 1-17, 2016.

[2] L. Yu, R. François, and R. Gagné, "Influence of steel-concrete interface defects induced by top-casting on development of chloride-induced corrosion in RC beams under sustained loading," Materials \& Structures, vol. 49, no. 12, pp. 5169-5181, 2016.

[3] M. Subhani and R. Al-Ameri, "Strength reduction in square columns confined with CFRP under marine environment," Composites Part B: Engineering, vol. 97, pp. 183-192, 2016.
[4] K. Suh, G. Mullins, R. Sen, and D. Winters, "Effectiveness of fiber-reinforced polymer in reducing corrosion in marine environment," ACI Structural Journal, vol. 104, no. 1, pp. 76-83, 2007.

[5] A. Agarwal, S. J. Foster, and E. Hamed, "Testing of new adhesive and CFRP laminate for steel-CFRP joints under sustained loading and temperature cycles," Composites Part B: Engineering, vol. 99, pp. 235-247, 2016.

[6] D. Borrie, X. L. Zhao, R. K. Singh Raman, and Y. Bai, "Fatigue performance of CFRP patched pre-cracked steel plates after extreme environmental exposure," Composite Structures, vol. 153, pp. 50-59, 2016.

[7] J. Garzón-Roca, J. M. Sena-Cruz, P. Fernandes, and J. Xavier, "Effect of wet-dry cycles on the bond behaviour of concrete elements strengthened with NSM CFRP laminate strips," Composite Structures, vol. 132, pp. 331-340, 2015.

[8] M. A. G. Silva, M. T. Cidade, H. Biscaia, and R. Marreiros, "Composites and FRP-strengthened beams subjected to dry/wet and salt fog cycles," Journal of Materials in Civil Engineering, vol. 26, no. 12, 2014.

[9] K. Suh, G. Mullins, R. Sen, and D. Winters, "Effective repair for corrosion control using FRP wraps," Journal of Composites for Construction, vol. 14, no. 4, pp. 388-396, 2010.

[10] W.-C. Choi and H.-D. Yun, "Acoustic emission activity of CFRP-strengthened reinforced concrete beams after freezethaw cycling," Cold Regions Science \& Technology, vol. 110, pp. 47-58, 2015.

[11] L. Hong, R. M. Duo, S. Y. Wang, and L. X. Li, "Influence of freeze-thaw cycles on bonded interface performance between CFRP and high strength concrete," Applied Mechanics and Materials, vol. 638-640, pp. 1516-1520, 2014.

[12] F. Al-Mahmoud, J.-M. Mechling, and M. Shaban, "Bond strength of different strengthening systems-concrete elements under freeze-thaw cycles and salt water immersion exposure," Construction and Building Materials, vol. 70, pp. 399-409, 2014.

[13] N. F. Grace and S. B. Singh, "Durability evaluation of carbon fiber-reinforced polymer strengthened concrete beams: Experimental Study and Design," ACI Structural Journal, vol. 102, no. 1, pp. 40-53, 2005.

[14] D. Borrie, R. Raman, X.-L. Zhao, and N. Adnan, "Quantifying corrosion between Carbon Fibre Reinforced Polymers (CFRP) and steel caused by high temperature marine environments," Advances in Structural Engineering, vol. 17, no. 12, pp. 1761-1770, 2014.

[15] R. El-Hacha, M. F. Green, and G. R. Wight, "Effect of severe environmental exposures on CFRP wrapped concrete columns," Journal of Composites for Construction, vol. 14, no. 1, pp. 83-93, 2010.

[16] V. K. R. Kodur, L. A. Bisby, and S. H.-C. Foo, “Thermal behavior of fire-exposed concrete slabs reinforced with fiber-reinforced polymer bars," ACI Structural Journal, vol. 102, no. 6, pp. 799$807,2005$.

[17] G. Nossoni and R. Harichandran, "Current efficiency in accelerated corrosion testing of concrete," Corrosion, vol. 68, no. 9, pp. 801-809, 2012.

[18] M. Hussein and T. M. Fawzy, "Structural performance of CFRPstrengthened RC slabs in a corrosive environment," Journal of Composites for Construction, vol. 14, no. 6, pp. 865-869, 2010.

[19] T. A. El Maaddawy and K. A. Soudki, "Effectiveness of impressed current technique to simulate corrosion of steel reinforcement in concrete," Journal of Materials in Civil Engineering, vol. 15, no. 1, pp. 41-47, 2003. 
[20] M. Badawi and K. Soudki, "Control of corrosion-induced damage in reinforced concrete beams using carbon fiber-reinforced polymer laminates," Journal of Composites for Construction, vol. 9, no. 2, pp. 195-201, 2005.

[21] M. Pour-Ghaz, O. B. Isgor, and P. Ghods, "Quantitative interpretation of half-cell potential measurements in concrete structures," Journal of Materials in Civil Engineering, vol. 21, no. 9, pp. 467-475, 2009.

[22] N. Zhuang, Y. Zhou, and H. Sun, "Effects of steel reinforcement corrosion on carbon-fibre-reinforced polymer repaired slabs," Proceedings of the Institution of Civil Engineers-Structures and Buildings, vol. 169, no. 1, pp. 46-53, 2016.

[23] F. Debieb, L. Courard, S. Kenai, and R. Degeimbre, "Mechanical and durability properties of concrete using contaminated recycled aggregates," Cement and Concrete Composites, vol. 32, no. 6, pp. 421-426, 2010 

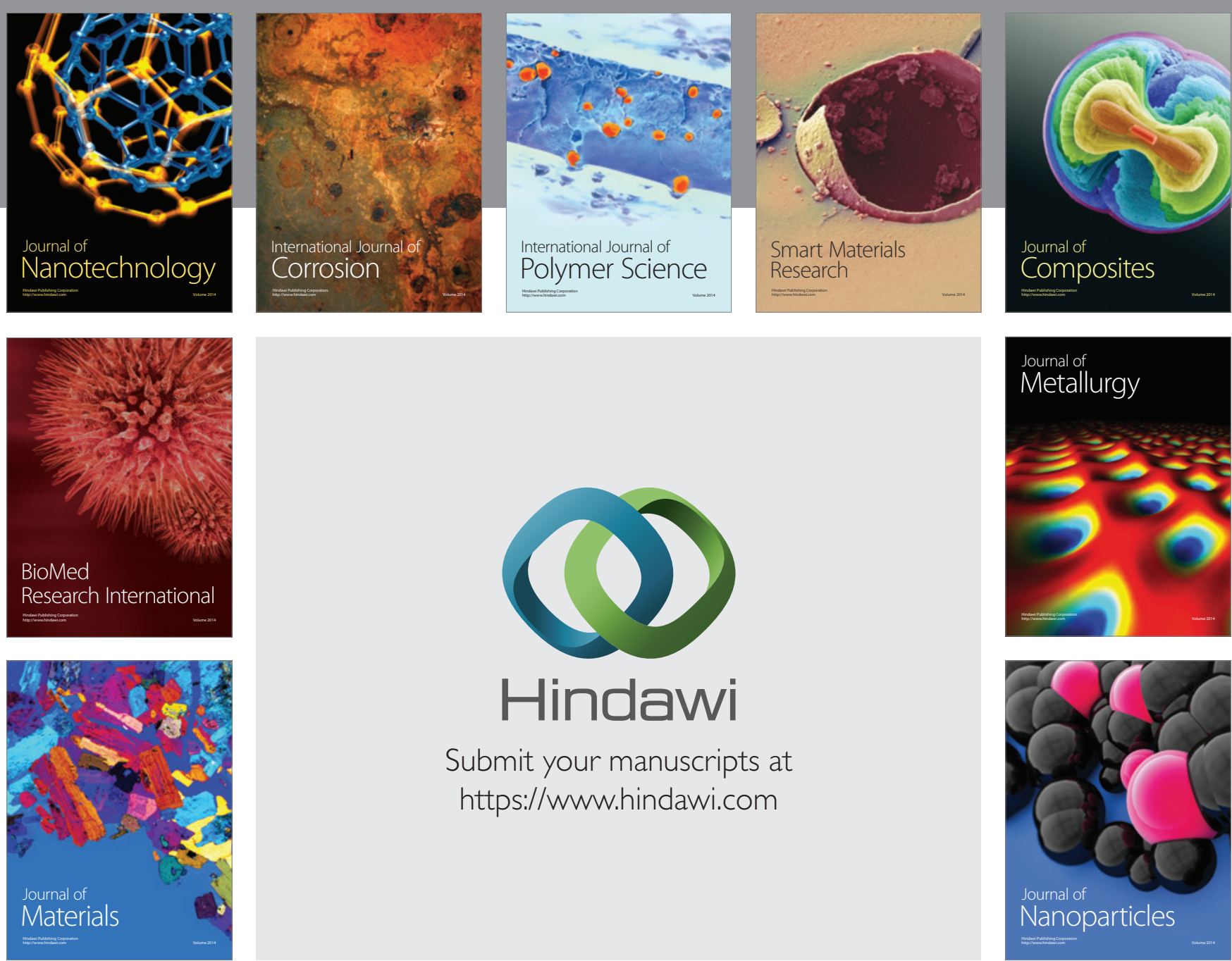

\section{Hindawi}

Submit your manuscripts at

https://www.hindawi.com

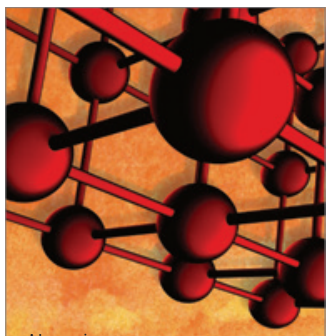

Materials Science and Engineering
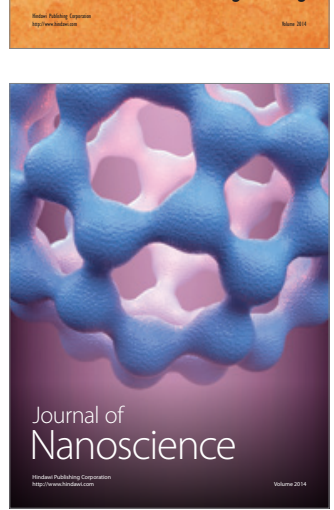
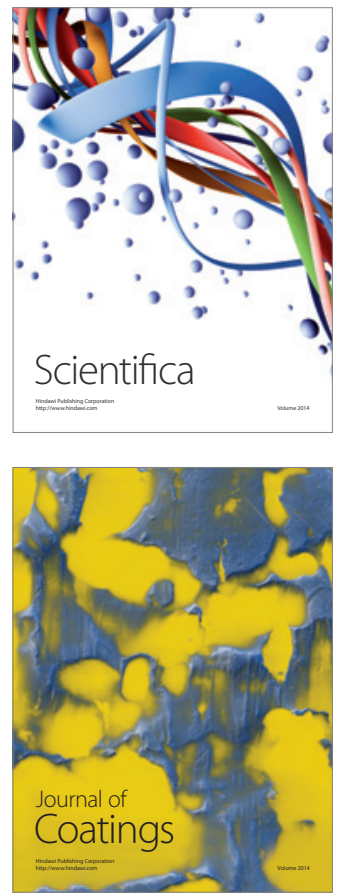
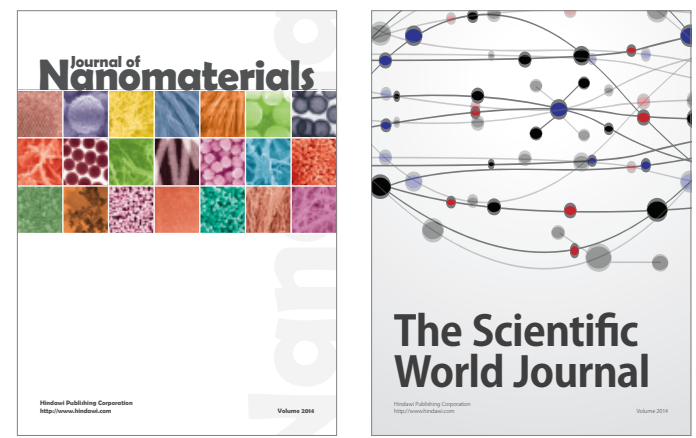

The Scientific World Journal
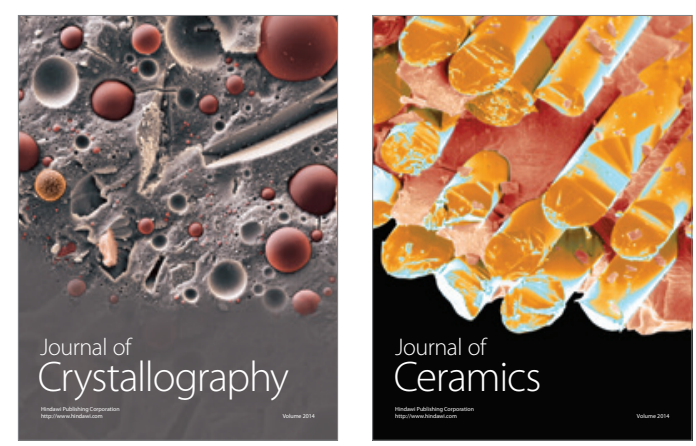
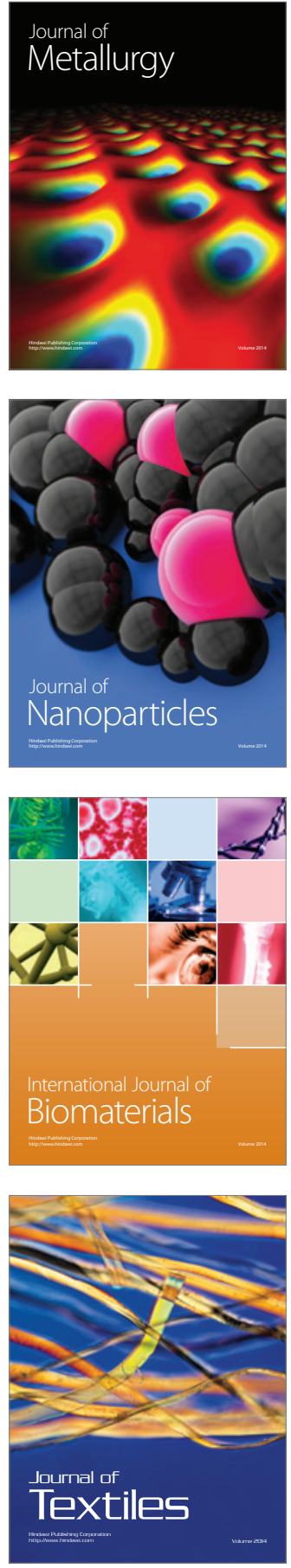